University of Nebraska - Lincoln

DigitalCommons@University of Nebraska - Lincoln

Faculty Publications in Food Science and Technology

Food Science and Technology Department

2010

\title{
Functionality of chemically modified wild-type, partial waxy and waxy starches from tetraploid wheats
}

\author{
L. E. Hansen \\ USDA-ARS
}

David S. Jackson

University of Nebraska-Lincoln, djackson1@unl.edu

R. L. Wehling

University of Nebraska-Lincoln, rwehling1@unl.edu

Robert A. Graybosch

University of Nebraska-Lincoln, bob.graybosch@ars.usda.gov

Follow this and additional works at: https://digitalcommons.unl.edu/foodsciefacpub

Part of the Food Science Commons

Hansen, L. E.; Jackson, David S.; Wehling, R. L.; and Graybosch, Robert A., "Functionality of chemically modified wild-type, partial waxy and waxy starches from tetraploid wheats" (2010). Faculty Publications in Food Science and Technology. 108.

https://digitalcommons.unl.edu/foodsciefacpub/108

This Article is brought to you for free and open access by the Food Science and Technology Department at DigitalCommons@University of Nebraska - Lincoln. It has been accepted for inclusion in Faculty Publications in Food Science and Technology by an authorized administrator of DigitalCommons@University of Nebraska - Lincoln. 


\title{
Functionality of chemically modified wild-type, partial waxy and waxy starches from tetraploid wheats
}

\author{
L.E. Hansen ${ }^{\text {a }}$, D.S. Jackson ${ }^{\mathrm{b}}$, R.L. Wehling ${ }^{\mathrm{b}}$, R.A. Graybosch ${ }^{\mathrm{a}, *}$ \\ ${ }^{a}$ USDA-ARS, 314 Biochemistry Hall, University of Nebraska-Lincoln, East Campus, Lincoln, NE 68583, USA \\ ${ }^{\mathrm{b}}$ Department of Food Science and Technology, University of Nebraska-Lincoln, NE 68583-0919, USA
}

\section{A R T I C L E I N F O}

\section{Article history:}

Received 11 September 2009

Received in revised form

3 February 2010

Accepted 10 February 2010

\section{Keywords:}

Tetraploid wheat

Starch

Functional properties

Amylose

Waxy alleles

Cross-linking

Substitution

Modified starches

\begin{abstract}
A B S T R A C T
Partial waxy (reduced-amylose) and fully waxy (amylose-free) tetraploid durum wheats (Triticum turgidum L. var durum) were developed by introgression of null alleles at the $W x-A 1$ and $W x-B 1$ loci from common hexaploid wheat (Triticum aestivum L.). Purified starches were obtained from each genotype, and chemically modified by: 1) cross-linking with phosphorus oxychloride, 2) substitution with propylene oxide, and 3) sequential cross-linking with phosphorus oxychloride followed by substitution with propylene oxide. Functional properties were compared to blends of waxy and wild-type durum starches of known amylose contents. Significant differences in functionality were observed amongst the genotypes and blends after each modification. Waxy ( $0 \%$ amylose) and wild-type (30\% amylose) typically were at the extremes of the observed ranges of functional properties. In general, the functional properties of the chemically modified starches were dependent upon amylose content. Starches from $W x-B 1$ null lines (24\% amylose), were an exception. After substitution, such starches had the significantly highest value for RVA final viscosity, and generally performed in a manner similar to starch blends of $12-18 \%$ amylose.
\end{abstract}

Published by Elsevier Ltd.

\section{Introduction}

Wild-type durum wheat (Triticum turgidum L. var. durum) produces two granule-bound - starch-synthase (GBSS, E.C. 2.4.1.242) isoforms of apparent molecular weight approximating $60 \mathrm{kDa}(W x-A 1 \sim 59.6$ and $W x-B 1 \sim 56.9 \mathrm{kDa}$ ) (Yamamori et al., 1995). $W x-A 1$ and $W x-B 1$ null lines each produce only one of the GBSS isoforms, and waxy genotypes produce no GBSS.

Although development of waxy and partial waxy durum wheat (Delwiche et al., 2006; Vignaux et al., 2004) has provided a novel starch for food or industrial use, functionalities may be enhanced by altering the granule characteristics with chemical modifications (BeMiller and Whistler, 1996; Patil and Meschi, 2008; Thomas and Atwell, 1999). In general, waxy starches are not directly used in foods; they are first stabilized via chemical modification (Reddy and Seib, 2000). When waxy starch is cross-linked, the effects include retention of gel clarity during refrigeration, viscosity retention in acidic foods, increased pasting temperature, retention of granule structure, reduced syneresis, reduced crumb staling, resistance to gel separation during freeze-thaw cycling, reduced

\footnotetext{
* Corresponding author. Tel.: +1 402472 1563; fax: +1 4024724020 .

E-mail address: bob.graybosch@ars.usda.gov (R.A. Graybosch).
}

gel firmness, increased gel adhesion, and other functional variations. These changes are due to increased water retention and polymer chain mobility restriction which slows the development of retrogradation, and depends upon the degree of cross-linkage (BeMiller and Whistler, 1996; Patil and Meschi, 2008; Thomas and Atwell, 1999). Cross-linked starch applications include gum gel confections, hard confection coating, clear decorative gels, fruit glaze, canned sauces, canned gravies, uniform heating of canned red beans in a retort, refrigerated and frozen desserts, frozen fruit pie, frozen dinner sauces and gravies, meat coatings, retarded staling of baked products, retained integrity of frozen bread products, pharmaceutical and edible films (BeMiller and Whistler, 1996; Patil and Meschi, 2008; Thomas and Atwell, 1999). Digestion resistant starch (RS4), also produced by chemical cross-linking (Shin et al., 2004; Woo and Seib, 2002), may have application as a form of dietary fiber.

Previous investigations have examined the characteristics of chemically modified waxy or partial waxy hexaploid wheat (Triticum aestivum L.) starches. Reddy and Seib (1999) compared the response of starches from two partial waxy wheat cultivars to wildtype wheats. The range of amylose content variation in the starches used, however, was slight. Reddy and Seib (2000) compared waxy hexaploid wheat to waxy maize (Zea mays L.) starch after chemical modification. Kiribuchi-Otobe et al. (2006) cross-linked two waxy 
hexaploid wheat lines carrying different mutant alleles at the $W x$ $D 1$ locus. However, no systematic comparison of the effects of durum wheat $W x$ genotypes on modified starch properties has been reported. The intent of the present investigation, therefore, was to determine whether different $W x$ genotypes of durum (tetraploid) wheat respond differently to chemical modification, and, if so, whether they may be used to produce starches with different functional properties. Additionally, the effects of both intra-granular amylose content variation, determined by genotype, and inter-granular amylose variation, created by blending of waxy and wild-type starches, were investigated.

\section{Experimental}

\subsection{Wheat and starch samples}

Sets of wild-type, partial waxy ( $W x-A 1$ null or $W x-B 1$ null), and waxy ( $W x-A 1$ and $W x-B 1$ double-null) durum wheat lines were developed in 4 genetic backgrounds (Delwiche et al., 2006). Bulked segregant analysis (Quarrie et al., 1999) was used to evaluate the effects of the tetraploid $W x$ loci genotypes. Samples were composited by genotype across genetic backgrounds. Separate composite samples were produced for each crop year. Additional details on plant culture, milling and starch extraction have been described previously (Hansen et al., in press). Percent amylose content of the isolated starches was determined by the dual wavelength amylose assay (Zhu et al., 2007). Waxy and wild-type starches were blended by weight to approximately 30\% (wild-type), $24 \%, 18 \%, 12 \%, 6 \%$, and $0 \%$ (waxy) amylose retaining crop year identity.

\subsection{Chemical modifications}

All native starches were modified by cross-linking with phosphorus oxychloride (Reddy and Seib, 2000; Woo and Seib, 2002) at an addition amount of $0.016 \%$ phosphorus oxychloride/starch (by weight). Samples were randomized, and reactions conducted in triplicate using $10 \mathrm{~g}$ dwb, starch samples. Starch P content of both native and cross-linked samples was determined by an independent commercial laboratory (Medallion Labs, Minneapolis, MN) and reported as ppm (dwb). Substitution was accomplished using 4.15\% (of starch weight) propylene oxide (Johnson, 1969; Kesler and Hjermstad, 1964; Leegwater and Luten, 1971). The degree of substitution for hydroxypropylation was determined by colorimetry (Johnson, 1969). Finally, all native starches were each modified sequentially by phosphorus oxychloride cross-linking followed by propylene oxide substitution on three randomly selected samples (Reddy and Seib, 2000; Woo and Seib, 2002). All reactions again were conducted in triplicate.

\subsection{Functional and physical properties}

Rapid Visco Analysis (RVA) utilized the Series 4 Rapid Visco Analyzer (Newport Scientific Pty. Ltd, Warriewood, NSW, Australia) with viscosity expressed in centiPoise $(\mathrm{cP})$, time in minutes (min) and temperature in degrees Celsius $\left({ }^{\circ} \mathrm{C}\right)$. Standard Protocol 1 found in Applications: 6.1 "General pasting method using the Rapid Visco Analyser", and modified in 7.9 "RVA Cross-linked and Substituted Starch Method" was used on all cross-linked, substituted and sequentially modified starches (Newport Scientific, 1995). Each product from each of the three reactions for each of the chemical modifications of the native starch (genotypes and \% amylose blends) was pasted separately, again independently for each crop year.
Modified starch gel textural responses were observed with a TA. $X t 2 i$ Texture Analyzer (Texture Technologies Corp., Scarsdale, NY, USA). The force $\times$ time curves were integrated for gel strength $=$ Area 1 and adhesion $=$ Area 2 .

The temperatures and heat flow into the starch and water system during loss of crystallinity for all cross-linked, substituted and sequentially modified starches were performed using Differential Scanning Calorimetry (DSC) (Pedersen et al., 2007; Ratnayake and Jackson, 2006).

\subsection{Statistical analyses}

Statistical analyses were performed using PC-SAS (SAS Institute, Cary, NC) Analysis of variance was used to evaluate variation due to the main effects crop year, type (defined as genotypes, or intergranular blends of waxy with wild-type) and year by type interactions for each physical property within each chemical modification treatment. Mean responses were compared by computation of least significant differences $(p=0.05)$.

\section{Results and discussion}

\subsection{Chemical properties and modifications}

Mean amylose contents (Hansen et al., in press) of the four genotypes were: $27.90 \%$ ( $W x-A 1$ null), $24.25 \%$ ( $W x-B 1$ null), $29.85 \%$ (wild-type) and $0.00 \%$ (waxy). The dual wavelength method recorded no measurable amylose content in the waxy starch. There was a significant difference observed for mean amylose content of the three remaining genotypes, with that of the $W x-B 1$ null samples being significantly lower than that of the $W x-A 1$ null and wild-type samples. The latter two samples did not differ significantly from each other.

Respective mean P content of the waxy, wild-type $W x-A 1$ and $W x-B 1$ null lines native starches was 350, 647, 673 and 767 ppm (dwb). Waxy, wild-type, $W x-A 1$ and $W x-B 1$ cross-linked starches respectively averaged $84,301,261$ and 268 ppm P. The sequentially modified waxy, wild-type, $W x-A 1$ null and $W x$-B1 null starches respectively averaged 99, 110, 100 and 297 ppm P. Thus, P content of all starches fell well within the legal limits of $0.5 \%$ (Stephen et al., 2006). As most native starch $P$ content is in the form of phospholipid (Soulaka and Morrison, 2006), the lower P content of the modified starches likely arose from phospholipid leaching during reactions. Hexaploid wheat starch generally is reported to have a $\mathrm{P}$ content in the range of 500-600 ppm (Swinkels, 1985; Kasemsuwan and Jane, 1996; Raeker et al., 1998; Franco et al., 2002). Average durum wheat cultivar P contents were reported as 633 ppm (Soulaka and Morrison, 2006). Waxy and partial waxy hexaploid wheat starch $\mathrm{P}$ content generally is lower, and with reported values of less than $200 \mathrm{ppm}$ for waxy, and less than 500 ppm for partial waxy samples (Bertolini et al., 2003; Yasui et al., 1996). The partial waxy samples in the present study showed no reduction in $\mathrm{P}$ content relative to wild-type.

The mean molar substitution value for the hydroxypropylated starches was 0.040 , with a mean standard deviation of 0.01 , and no significant differences.

\subsection{Functionality}

ANOVA (not shown) detected no significant effects due to crop year or crop year $\times$ type interaction for RVA properties of crosslinked, substituted, or sequentially modified starches. The degree of cross-linking achieved in this study drastically diminished RVA viscosities of wild-type and partial waxy samples (Fig. 1, Table 1). Cross-linking of waxy starch, however, produced a product with 

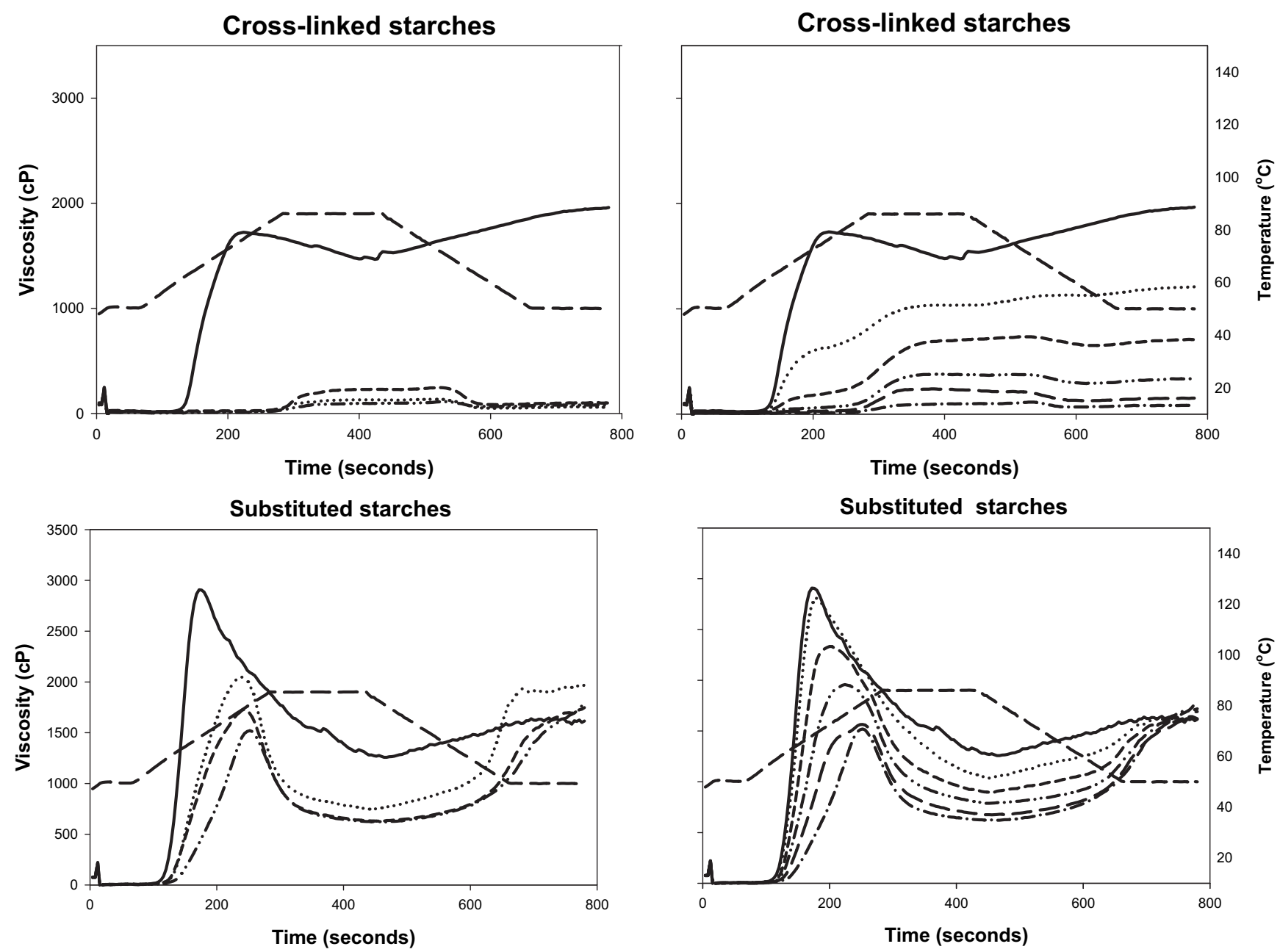

Substituted starches
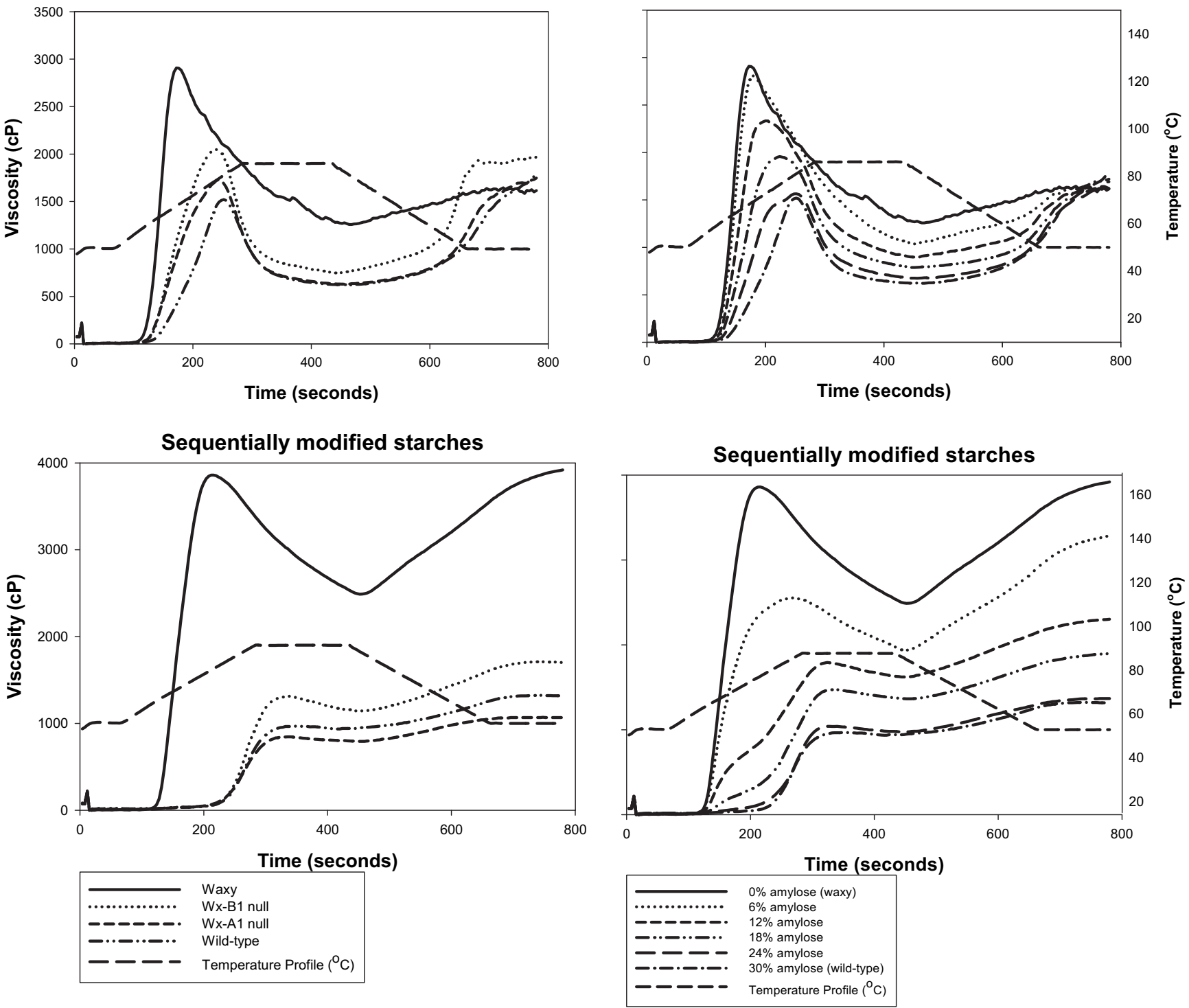

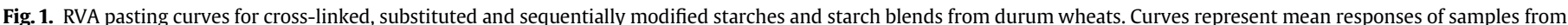
2003 to 2004 harvest years. 
Table 1

Means from Rapid Visco Analysis of cross-linked starches purified from tetraploid wheats grown in 2003 and 2004.

\begin{tabular}{lrrrrrll}
\hline Treatment $^{\mathrm{a}}$ & $\begin{array}{l}\mathrm{ViscP}^{\mathrm{b}} \\
(\mathrm{cP})\end{array}$ & \multicolumn{1}{c}{$\begin{array}{l}\text { ViscTr } \\
(\mathrm{cP})\end{array}$} & $\begin{array}{l}\text { Brakdn } \\
(\mathrm{cP})\end{array}$ & $\begin{array}{l}\text { ViscF } \\
(\mathrm{cP})\end{array}$ & $\begin{array}{l}\text { Setbak } \\
(\mathrm{cP})\end{array}$ & $\begin{array}{l}\text { PkTime } \\
(\mathrm{min})\end{array}$ & $\begin{array}{l}\text { TPaste } \\
\left({ }^{\circ} \mathrm{C}\right)\end{array}$ \\
\hline 6 & 1030 & 997 & 34 & 1194 & 198 & 6.5 & 52.3 \\
12 & 690 & 632 & 58 & 693 & 61 & 6.8 & 50.7 \\
18 & 374 & 282 & 93 & 329 & 48 & 6.3 & 51.5 \\
24 & 234 & 113 & 122 & 139 & 27 & 6.1 & 52.1 \\
AN & 227 & 71 & 156 & 91 & 20 & 6.5 & 51.7 \\
BN & 134 & 48 & 86 & 60 & 13 & 6.1 & 53.1 \\
WT & 74 & 39 & 35 & 55 & 17 & 6.6 & 52.7 \\
WX & 1834 & 1400 & 434 & 1960 & 560 & 5.6 & 50.5 \\
Mean & 575 & 447 & 127 & 565 & 118 & 6.3 & 51.8 \\
lsd & 571 & 287 & 315 & 405 & 140 & 0.7 & 1.9 \\
\hline
\end{tabular}

a $\mathrm{WX}=$ waxy genotype or $0 \%$ amylose, $\mathrm{WT}=$ wild-type genotype or $30 \%$ amylose, $\mathrm{AN}=W x-A 1$ null partial waxy genotype, $\mathrm{BN}=W x-B 1$ null partial waxy genotype, $6=6 \%$ amylose, $12=12 \%$ amylose, $18=18 \%$ amylose, $24=24 \%$ amylose.

${ }^{\mathrm{b}} \mathrm{ViscP}=$ peak viscosity; ViscTR = trough or hot paste viscosity; Brakdn = breakdown or the difference between peak viscosity and hot paste viscosity; ViscF = final or cold paste viscosity; Setbak = set back or the difference between hot paste viscosity and cold paste viscosity; PkTime = time from start of the run to peak viscosity; TPaste $=$ pasting temperature.

enhanced and stable RVA viscosities. The peak and final viscosities of cross-linked waxy starch were markedly higher than those of the remaining three genotypes. Peak and final viscosities of the blended cross-linked samples fell between the waxy and wild-type samples, and generally were proportional to amylose content. The cross-linking level employed in this study was within the range used by Reddy and Seib (2000) as typical of industrial applications.

Peak viscosity of waxy substituted starch also was statistically greater than that of all other samples (Table 2, Fig. 1), with the exception of the $6 \%$ amylose blend. Peak viscosities of substituted starches generally were proportional to amylose content, with one exception. Peak viscosity of the $W x$-B1 null substituted starch was significantly greater than that of the other genotypes, and nearly identical to that of the $18 \%$ blend, even though the Wx-B1 null sample had an amylose content of $24.25 \%$. Final RVA viscosity of the $W x-B 1$ null substituted starch was statistically greater than that of all other genotypes and blends. Final viscosities of substituted starches of all other genotypes and blends did not differ from each other. The $W x-B 1$ null native starch also displayed functional properties not in proportion to its amylose content (Hansen et al., in press). Peak times of all samples did not vary, with the exception

\section{Table 2}

Means from Rapid Visco Analysis of substituted starches from tetraploid wheats grown in 2003 and 2004.

\begin{tabular}{llllllll}
\hline Treatment $^{\mathrm{a}}$ & $\begin{array}{l}\mathrm{ViscP}^{\mathrm{b}} \\
(\mathrm{cP})\end{array}$ & $\begin{array}{l}\text { ViscTr } \\
(\mathrm{cP})\end{array}$ & $\begin{array}{l}\text { Brakdn } \\
(\mathrm{cP})\end{array}$ & $\begin{array}{l}\text { ViscF } \\
(\mathrm{cP})\end{array}$ & $\begin{array}{l}\text { Setbak } \\
(\mathrm{cP})\end{array}$ & $\begin{array}{l}\text { PkTime } \\
(\mathrm{min})\end{array}$ & $\begin{array}{l}\text { TPaste } \\
\left({ }^{\circ} \mathrm{C}\right)\end{array}$ \\
\hline 6.0 & 2836 & 1023 & 1813 & 1614 & 591 & 3.0 & 50.4 \\
12.0 & 2417 & 889 & 1529 & 1620 & 732 & 3.5 & 52.0 \\
18.0 & 2179 & 784 & 1394 & 1720 & 935 & 3.8 & 51.5 \\
24.0 & 1950 & 671 & 1278 & 1692 & 1020 & 4.0 & 51.0 \\
AN & 1953 & 627 & 1326 & 1748 & 1121 & 3.9 & 51.3 \\
BN & 2128 & 744 & 1384 & 1967 & 1223 & 3.9 & 51.2 \\
WT & 1591 & 616 & 975 & 1786 & 1170 & 4.1 & 50.6 \\
WX & 3043 & 1201 & 1843 & 1615 & 414 & 2.8 & 51.1 \\
Mean & 2262 & 820 & 1443 & 1720 & 901 & 3.6 & 51.1 \\
lsd & 254.8 & 62.2 & 148.1 & 132.6 & 104.7 & 0.2 & 0.7 \\
\hline
\end{tabular}

${ }^{a} \mathrm{WX}=$ waxy genotype or $0 \%$ amylose, $\mathrm{WT}=$ wild-type genotype or $30 \%$ amylose, $\mathrm{AN}=W x-A 1$ null partial waxy genotype, $\mathrm{BN}=W x-B 1$ null partial waxy genotype, $6=6 \%$ amylose, $12=12 \%$ amylose, $18=18 \%$ amylose, $24=24 \%$ amylose.

${ }^{\mathrm{b}}$ ViscP $=$ peak viscosity; ViscTR $=$ trough or hot paste viscosity; Brakdn = breakdown or the difference between peak and hot paste viscosities; ViscF = final or cold paste viscosity; Setbak = set back or the difference between hot paste viscosity and cold paste viscosity; PkTime = time from start of the run to peak viscosity; TPaste $=$ pasting temperature. that the waxy sample displayed a significantly shorter value; a similar observation was made for native waxy starch (Hansen et al., in press).

Relative to cross-linking alone, sequential modification increased the viscosity of all samples (Fig. 1, Table 3). Both peak and final viscosities of the waxy sequentially modified starch were markedly elevated and statistically greater than all other samples. Peak time of the waxy sample also was significantly lower than that of all other samples. Again, there was an amylose-dependent trend evident amongst the remaining samples and blends, with the exception once again of the $W x-B 1$ null sample. Peak and final viscosities of this sample did not differ from the $12 \%$ amylose blend. The observed final viscosities of the sequentially modified starches indicate food processers could achieve any desired response simply via mechanical blending of waxy and wild-type wheats. Reddy and Seib (1999) did not observe amylose-dependent responses when starches from two partial waxy wheats were compared to one wildtype sample. However, they used starches with only a narrow $(23 \%-28 \%)$ range of amylose content variation, the samples were not derived from common genetic backgrounds, and were not from wheats grown in the same environment. Thus, many confounding effects, removed in the present study, may have influenced their results.

\subsection{Texture}

No significant crop year or interactions were observed for gel texture measurements. Cross-linked starches showed few significant differences from each other (Table 4$)$. The $W x-A 1$ null sample produced a gel with an Area1 (gel strength) value significantly greater than that of the $W x-B 1$ null, but all other cross-linked starches did not differ from each other. Area2 (adhesion) values of cross-linked starches showed no significant differences.

After substitution or sequential modification, starches showed nearly identical responses. Significant differences were observed between waxy and wild-type samples for both Area1 and Area2, with wild-type displaying the greater values (Table 4). Area1 values for both modifications of all other samples showed amylosedependent absolute values, but rarely were statistically significant differences observed. Area2 values differed only between waxy and all other samples. Wild-type substitution and sequentially modified gels were stronger and displayed less adhesion than waxy samples.

\section{Table 3}

Means from Rapid Visco Analysis of sequentially modified starches purified from tetraploid wheats grown in 2003 and 2004.

\begin{tabular}{lrrrlrll}
\hline Treatment $^{\mathrm{a}}$ & $\begin{array}{l}\text { ViscP }^{\mathrm{b}} \\
(\mathrm{cP})\end{array}$ & \multicolumn{1}{c}{$\begin{array}{l}\text { ViscTr } \\
(\mathrm{cP})\end{array}$} & $\begin{array}{l}\text { Brakdn } \\
(\mathrm{cP})\end{array}$ & $\begin{array}{l}\text { ViscF } \\
(\mathrm{cP})\end{array}$ & $\begin{array}{l}\text { Setbak } \\
(\mathrm{cP})\end{array}$ & $\begin{array}{l}\text { PkTime } \\
(\mathrm{min})\end{array}$ & $\begin{array}{l}\text { TPaste } \\
\left({ }^{\circ} \mathrm{C}\right)\end{array}$ \\
\hline 6 & 2700 & 1932 & 768 & 3283 & 1351 & 4.6 & 52.3 \\
12 & 1800 & 1616 & 184 & 2303 & 687 & 5.6 & 51.2 \\
18 & 1482 & 1359 & 123 & 1898 & 539 & 5.6 & 51.2 \\
24 & 1039 & 936 & 102 & 1351 & 414 & 5.7 & 51.6 \\
AN & 855 & 785 & 70 & 1067 & 282 & 6.0 & 51.1 \\
BN & 1765 & 1474 & 290 & 2802 & 1327 & 5.9 & 51.7 \\
WT & 975 & 930 & 45 & 1317 & 387 & 5.9 & 52.9 \\
WX & 3886 & 2488 & 1399 & 3920 & 1432 & 3.6 & 50.8 \\
Mean & 1829 & 1451 & 378 & 2261 & 812 & 5.4 & 51.6 \\
lsd & 856 & 521 & 494 & 1517 & 1023 & 1.1 & n.s. \\
\hline
\end{tabular}

a $\mathrm{WX}=$ waxy genotype or $0 \%$ amylose, $\mathrm{WT}=$ wild-type genotype or $30 \%$ amylose, $\mathrm{AN}=W x-A 1$ null partial waxy genotype, $\mathrm{BN}=W x-B 1$ null partial waxy genotype, $6=6 \%$ amylose, $12=12 \%$ amylose, $18=18 \%$ amylose, $24=24 \%$ amylose.

${ }^{\mathrm{b}} \mathrm{ViscP}=$ peak viscosity; ViscTR $=$ trough or hot paste viscosity; Brakdn = breakdown or the difference between peak and hot paste viscosities; $\mathrm{ViscF}=$ final or cold paste viscosity; Setbak = set back or the difference between hot paste viscosity and cold paste viscosity; PkTime = time from start of the run to peak viscosity; TPaste $=$ pasting temperature. 
Table 4

Means from texture evaluation of gels from chemically modified starches purified from tetraploid wheat grown in 2003 and 2004.

\begin{tabular}{|c|c|c|c|c|c|c|}
\hline \multirow[t]{2}{*}{ Treatment $^{\mathrm{a}}$} & \multicolumn{2}{|c|}{ Cross-linked } & \multicolumn{2}{|c|}{ Substituted } & \multicolumn{2}{|c|}{ Sequentially modified } \\
\hline & $\begin{array}{l}\text { Area } 1^{b} \\
(\mathrm{Ns})\end{array}$ & Area2 (Ns) & $\begin{array}{l}\text { Area1 } \\
\text { (Ns) }\end{array}$ & $\begin{array}{l}\text { Area2 } \\
\text { (Ns) }\end{array}$ & $\begin{array}{l}\text { Area1 } \\
\text { (Ns) }\end{array}$ & $\begin{array}{l}\text { Area2 } \\
\text { (Ns) }\end{array}$ \\
\hline 6 & 1.02 & -0.49 & 0.70 & -0.31 & 1.60 & -0.66 \\
\hline 12 & 1.32 & -0.51 & 1.06 & -0.31 & 2.72 & -0.36 \\
\hline 18 & 1.53 & -0.42 & 2.45 & -0.21 & 4.27 & -0.18 \\
\hline 24 & 1.52 & -0.39 & 2.97 & 0.22 & 5.46 & 0.18 \\
\hline AN & 2.07 & -0.38 & 2.63 & 0.33 & 5.56 & -0.06 \\
\hline $\mathrm{BN}$ & 0.95 & -0.37 & 2.72 & -0.11 & 4.68 & 0.95 \\
\hline WT & 1.81 & -0.41 & 3.45 & 0.66 & 9.77 & 0.49 \\
\hline WX & 1.36 & -0.41 & 0.95 & -0.17 & 2.60 & -0.60 \\
\hline Mean & 1.45 & -0.42 & 2.10 & 0.01 & 4.58 & -0.03 \\
\hline lsd & 0.90 & n.s. & 1.30 & 0.31 & 2.24 & 0.86 \\
\hline
\end{tabular}

${ }^{\text {a }} \mathrm{WX}=$ waxy genotype or $0 \%$ amylose, $\mathrm{WT}=$ wild-type genotype or $30 \%$ amylose $\mathrm{AN}=W x-A 1$ null partial waxy genotype, $\mathrm{BN}=W x-B 1$ null partial waxy genotype, $6=6 \%$ amylose, $12=12 \%$ amylose, $18=18 \%$ amylose, $24=24 \%$ amylose

b Area $1=$ gel compression to $4 \mathrm{~mm}$ (Newton seconds), Area $2=$ reverse stroke (Newton seconds).

Wild-type samples were "cleaner releasing", as indicated by the more negative values for Area2.

\subsection{Thermal transition}

Across the three types of chemical modification, similar responses were observed. DSC peak temperatures were greatest in the waxy samples, as was $\Delta H$, (enthalpy) (Table 5). The two partial waxy samples were similar to wild-type, and the blended samples displayed amylose-dependent results. This suggests that even after chemical modification, the most important factor governing thermal transitions was the degree of crystallinity of the sample, and was inversely related to amylose content. Waxy starch, composed entirely of $100 \%$ amylopectin, required the highest energy input for achievement of the thermal transition.

In general, functional properties of the modified starches behaved in amylose content-dependent fashions. Waxy and wildtype samples generally differed from each other, and blends ranging from $6 \%$ to $24 \%$ amylose behaved in a concentration predicted manner. End-users could, therefore, adjust the ratio of amylose to obtain desired end-results, especially in terms of starch pasting properties. Altering amylose content, other than at the

Table 5

Means from Differential Scanning Calorimetry evaluation of modified starches purified from tetraploid wheats grown in 2003 and 2004.

\begin{tabular}{|c|c|c|c|c|c|c|}
\hline \multirow[t]{2}{*}{ Treatment $^{\mathrm{a}}$} & \multicolumn{2}{|c|}{ Cross-linked } & \multicolumn{2}{|c|}{ Substituted } & \multicolumn{2}{|c|}{$\begin{array}{l}\text { Sequential cross- } \\
\text { linking and } \\
\text { substitution }\end{array}$} \\
\hline & $\begin{array}{l}\text { Peak }^{\mathrm{b}} \\
\left({ }^{\circ} \mathrm{C}\right)\end{array}$ & $\begin{array}{l}\text { Enthalpy } \\
(\mathrm{J} / \mathrm{g})\end{array}$ & $\begin{array}{l}\text { Peak } \\
\left({ }^{\circ} \mathrm{C}\right)\end{array}$ & $\begin{array}{l}\text { Enthalpy } \\
(\mathrm{J} / \mathrm{g})\end{array}$ & $\begin{array}{l}\text { Peak } \\
\left({ }^{\circ} \mathrm{C}\right)\end{array}$ & $\begin{array}{l}\text { Enthalpy } \\
(\mathrm{J} / \mathrm{g})\end{array}$ \\
\hline 6 & 60.7 & 15.8 & 56.3 & 13.7 & 58.4 & 15.3 \\
\hline 12 & 60.6 & 15.2 & 56.0 & 13.7 & 58.0 & 15.1 \\
\hline 18 & 59.9 & 15.2 & 56.0 & 13.0 & 57.1 & 14.6 \\
\hline 24 & 59.5 & 14.4 & 55.4 & 12.3 & 58.1 & 13.6 \\
\hline AN & 59.0 & 13.8 & 55.4 & 13.3 & 56.6 & 12.5 \\
\hline $\mathrm{BN}$ & 59.2 & 13.9 & 55.3 & 13.6 & 58.6 & 14.6 \\
\hline WT & 58.3 & 12.9 & 55.2 & 11.7 & 56.3 & 13.4 \\
\hline WX & 60.9 & 16.8 & 54.9 & 13.7 & 58.4 & 15.3 \\
\hline Mean & 59.8 & 14.7 & 55.6 & 13.1 & 57.7 & 14.3 \\
\hline lsd & 0.7 & 1.4 & 0.72 & 1.60 & 2.1 & 1.5 \\
\hline
\end{tabular}

${ }^{\text {a }} \mathrm{WX}=$ waxy genotype or $0 \%$ amylose, $\mathrm{WT}=$ wild-type genotype or $30 \%$ amylose, $\mathrm{AN}=W x-A 1$ null partial waxy genotype, $\mathrm{BN}=W x-B 1$ null partial waxy genotype, $6=6 \%$ amylose, $12=12 \%$ amylose, $18=18 \%$ amylose, $24=24 \%$ amylose.

b Peak = peak transition temperature, Enthalpy = heat of transition per unit mass. extremes of waxy and wild-type, did little to alter starch gel textural properties. On the other hand, if very large departures from wild-type are desired, waxy wheat starch offers a new substrate for modified starch production.

Partial waxy ( $W x-A 1$ and $W x-B 1$ nulls) starch functionalities generally performed intermediately between the waxy and wildtype starches, but often with values less than expected by comparison with the inter-granule amylose blends. $W x-A 1$ null (intra-granule $26 \%$ amylose) was occasionally found to have values not significantly different from the $24 \%$ inter-granule amylose blend, and $W x-B 1$ null (intra-granule $24 \%$ amylose) was found to have values not significantly different from the $12 \%$ or $18 \%$ intergranule amylose blends. This indicated amylose content changes within the starch granule had a greater affect on functionality response than the same amylose content changes effected by blending of wild-type and waxy starch granules. Although there may be other factors, amylose reduced within the granule may be less available due to entrapping amylopectin structure than amylose in the wild-type granules diluted with amylose-free waxy granules in the blends.

By reagent selection the functional properties of partial waxy genotypes and \% amylose blends of wild-type with waxy wheat starches may be altered for specific end use applications. At the reagent concentrations utilized, waxy and wild-type were very frequently among the extreme significance groups for the functionality properties. The most notable exception was RVA final viscosity for the substituted pasting curves where $W x-B 1$ null (intra-granule, 24\% amylose) was the only significantly different and high value.

\section{References}

BeMiller, J.N., Whistler, R.L., 1996. In: Fennema, O.R. (Ed.), Food Chemistry, third ed. Marcel Dekker, Inc., New York, New York, pp. 157-204.

Bertolini, A.C., Souza, E., Nelson, J.E., Huber, K.C., 2003. Composition and reactivity of A- and B-type starch granules of normal, partial waxy, and waxy wheat. Cereal Chemistry 80, 544-549.

Delwiche, S.R., Graybosch, R.A., Hansen, L.E., Souza, E., Dowell, F.E., 2006. Single kernel near-infrared analysis of tetraploid (durum) wheat for classification of the waxy condition. Cereal Chemistry 83, 287-292.

Franco, C.M.L., Wong, K.S., Yoo, S.H., Jane, J.L., 2002. Structural and functional characteristics of selected soft wheat starches. Cereal Chemistry 79, 243-248.

Hansen, L.E., Jackson, D.S., Wehling, R.L., Wilson, J.D., Graybosch, R.A. Functionality of native tetraploid wheat starches: effects of waxy loci alleles and amylose concentration in blends. Journal of Cereal Science, in press, doi:10.1016/j.jcs. 2010.02.015

Johnson, D.P., 1969. Spectrophotometric determination of the hydroxypropyl group in starch ethers. Analytical Chemistry 41, 859-860.

Kiribuchi-Otobe, C., Fujita, M., Matsunaka, H., Sekine, M., 2006. Properties of crosslinked starch from waxy mutant wheat Tanikei A6599-4. Cereal Chemistry 83, 590-594.

Kasemsuwan, T., Jane, J.L., 1996. Quantitative method for the survey of starch phosphate derivatives and starch phospholipids by ${ }^{31} \mathrm{P}$ nuclear magnetic resonance spectroscopy. Cereal Chemistry 73, 702-707.

Kesler, C.C., Hjermstad, E.T., 1964. Hydroxyethyl and hydroxypropyl starch. pp. 304-306. In: Whistler, R.L. (Ed.), Methods in Carbohydrate Chemistry, vol. 4. Academic Press, New York, USA.

Leegwater, D.C., Luten, J.B., 1971. A study on the in vitro digestibility of hydroxypropyl starches by pancreatin. Starch/Staerke 23, 430-432.

Newport Scientific Pty. Ltd, 1995. Applications Manual. Newport Scientific Pty. Ltd, Warriewood, NSW, Australia.

Patil, S.K., Meschi, M.A., 2008. Formulating for texture and viscosity. Prepared Foods $177,112-124$

Pedersen, J.F., Graybosch, R.A., Funnell, D.L., 2007. Occurrence of the waxy alleles wxa and $w x b$ in waxy sorghum plant introductions and their effect on starch thermal properties. Crop Science 47, 1927-1933.

Quarrie, S., Lazic-Jancic, V., Kovacevic, D., Steed, A., Pekic, S., 1999. Bulk segregant analysis with molecular markers and its use for improving drought resistance in maize. Journal of Experimental Botany 50, 1299-1306.

Raeker, M.Ö., Gaines, C.S., Finney, P.L., Donelson, T., 1998. Granule size distribution and chemical composition of starches from 12 soft wheat cultivars. Cereal Chemistry 75, 721-728.

Ratnayake, W.S., Jackson, D.S., 2006. Gelatinization and solubility of corn starch during heating in excess water: new insights. Journal of Agricultural Food Chemistry 54, 3712-3716. 
Reddy, I., Seib, P.A., 1999. Pasting properties of modified starches from partial waxy wheats. Cereal Chemistry 76, 341-349.

Reddy, I., Seib, P.A., 2000. Modified waxy wheat starch compared to modified waxy corn starch. Journal of Cereal Science 31, 25-39.

Shin, M., Song, J., Seib, P.A., 2004. In vitro digestibility of cross-linked starches - RS4. Starch/Staerke 56, 478-483.

Soulaka, A.B., Morrison, W.R., 2006. The amylose and lipid contents, dimensions, and gelatinization characteristics of some wheat starches and their A- and B-granule fractions. Journal of the Science of Food and Agriculture 36, 709-718.

Stephen, A.M., Philips, G.M., Williams, P.A. (Eds.), 2006. Food Polysaccharides and Their Applications, second ed. CRC/Taylor \& Francis, Boca Raton, FL.

Swinkels, J.J.M., 1985. Composition and properties of commercial native starches. Starch 37, 1-5.

Thomas, D.J., Atwell, W.A., 1999. Starches. Eagan Press, St. Paul, MN.
Vignaux, N., Doehlert, D.C., Hegstad, J., Elias, E.M., McMullen, M.S., Grant, L.A. Kianian, S.F., 2004. Grain quality characteristics and milling performance of full and partial waxy durum lines. Cereal Chem. 81, 377-383.

Woo, K.S., Seib, P.A., 2002. Cross-linked resistant starch: preparation and properties 1. Cereal Chemistry 79, 819-825.

Yamamori, M., Nakamura, T., Nagamine, T., 1995. Polymorphism of two waxy proteins in the emmer group of tetraploid wheat, T. dicoccoides, T. dicoccum, and T. durum. Plant Breeding 114, 215-218.

Yasui, T., Matsuki, J., Sasaki, T., Yamamori, M., 1996. Amylose and lipid contents, amylopectin structure, and gelatinisation properties of waxy wheat (Triticum aestivum L.) starch. Jounal of Cereal Science 24, 131-137.

Zhu, T., Jackson, D.S., Wehling, R.L., Geera, B., 2007. Comparison of amylose determination methods and the development of a dual wavelength iodine binding technique. Cereal Chemistry 85, 51-58. 